\title{
Development of a Web-Based Information Service Platform for Protected Crop Pests
}

\author{
Chong Huang and Haiguang Wang* \\ Department of Plant Pathology, China Agricultural University, Beijing, 100193 P.R. China \\ Tel.: +86-10-62733877 \\ wanghaiguang@cau .edu.cn
}

\begin{abstract}
With the rapid development of internet technology and protected cultivation in China, it is impending to implement a web-based information service system to spread professional agricultural knowledge. In this study, a 3-layer architecture web-based information service platform (ISP) for protected crop pests was developed using HTML, JavaScript and active server page (ASP). The platform included the information management module, the aided diagnosis module, the module of instructions for pest control, the technology BBS module, the system management module and the relative references module. Two logical algorithms, namely, identification key method and fuzzy diagnostic method, were designed for aided diagnosis of protected crop pests. The ISP could provide a technological platform for decision makers, agricultural technique extension workers and farmers. It is favorable to the effective management of protected crop pests.
\end{abstract}

Keywords: Information service platform, protected crop, pest, aided diagnosis.

\section{Introduction}

In recent years, protected cultivation has been developing rapidly in China. Protected agriculture could provide off-season vegetable, fruit and fresh flowers to meet people's increasingly living demand. Meanwhile, protected agriculture has enhanced the related farmers' income, which makes contributions to solving the question of "three agriculture", namely the question of agriculture, countryside and farmers. However, high-level technique and management are indispensable in protected agriculture. Therefore, it is very important to spread the professional knowledge of protected agricultural production.

Protected cultivation has important influence on the occurrence and epidemics of protected crop pests. It provides favorable conditions for the outbreak of the pests. It makes the pests occur during the off-season or in the areas where they could not occur before. Especially, the pest problems are very severe in the fields where protected cultivation has been applying for many years. Protected crop pests could reduce the crop yield or affect the quality of agricultural products, and then reduce the income of the farmers. In addition, some pests occurring severely in protected environment

\footnotetext{
* Corresponding author.
} 
could provide initial inoculums for the crops growing in the open fields. Therefore, the issue of the pests is a main obstacle for the healthy development of protected agriculture. To solve this issue, it is important to identify or diagnose the pests in a timely and accurate manner, and take suitable control measures consequently. However, the lack of agricultural technique extension workers in China makes farmer training technical guidance facing many difficulties. Although the farmers could get some knowledge through watching TV, listening to broadcast or reading the technological books, they could not timely get related professional knowledge or communicate with related agricultural technique workers, so in most cases they could not solve the problems in the agricultural production that they have never met before. With the construction of agricultural informatization in China, internet construction in rural areas is developing rapidly. Some agricultural technique extension workers in the rural areas and some farmers can get access to internet conveniently and easily. Especially in the areas where protected agriculture has been developing well, the economic conditions are also good so that the extension workers and the farmers could obtain the agricultural knowledge and solve the problems that they meet in the agricultural production via internet. With the development and popularization of computer technology, the computers have been widely applied in the researches on plant protection [1, 2]. Some web-based plant pests information management systems have been developed $[3,4,5$, $6,7,8,9]$.These systems made the spread of agricultural knowledge and the solution of some practical agricultural problems more convenient and faster.

Using Delphi, we developed Information Retrieval and Aided Diagnosis System for Protected Crop Pests (IRADS-PCP) on the Windows operation system platform [10]. IRADS-PCP provided an opening and tree-shaped knowledge database for the information management of protected crop pests and for the retrieval of this kind of information in different ways. It is intelligent and useful for the diagnosis and the control of protected crop pests. However, IRADS-PCP is a software system and could only be run on personal computer so that it is not very easy and convenient for the users. In this study, we developed a web-based information service platform (ISP) for protected crop pests on the base of IRADS-PCP. The use of the internet enables the users to get information more efficiently and rapidly. The platform can provide the latest information of protected crop pests and pest control measures to the users so that they could identify or diagnose the crop pests and take suitable control measures timely and efficiently.

\section{The Structure of the Information Service Platform}

\subsection{The Web-Based Information Service Platform}

The web-based information service platform (ISP) has been designed as a 3-layer architecture as shown in Fig. 1. The ISP consists of three layers: the user interface layer, the application layer and the database layer. The user interface layer running on an internet environment such as the Internet Explorer has been developed by HTML (Hypertext Markup Language), CSS (Cascading Style Sheets) and JavaScript with Microsoft FrontPage. This layer transfers the user's action to the application layer, and then the result from the application layer could be displayed on the Internet Explorer. The application layer uses the internet information server (IIS) and active 
server page (ASP). The IIS can response the requests from the users and send the corresponding results back to the users. All users connect the IIS through the internet and obtain information by submitting queries. The application layer includes some services applications and database applications programmed based on ASP. ASP is a widely-used scripting language that is suited to web development and can be embedded into HTML running on the internet information server. Actions services applications analyze the user's request from the IIS and the results are provided to the IPS DB algorithm and programs according to the requests. Then the ISP DB applications return the necessary data to the action services logic and programs. The database layer has been built on a SQL server which is a relational database management system, and provides data for information service including the pests' information data, research advance data and diagnosis characteristic values data, etc.

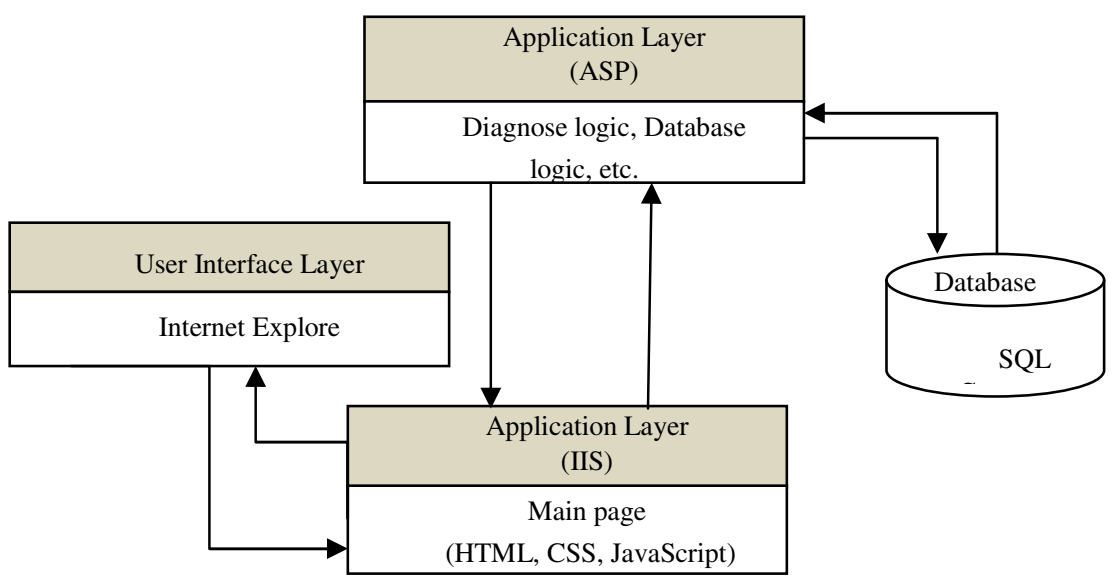

Fig. 1. The 3-layer architecture adopted in the web-based ISP

\subsection{The Main Logical Algorithm of the Web-Based ISP}

Two logical algorithms were adopted in the web-based ISP for the aided diagnosis: diagnose through binary tree structural taxonomic key (TK) and fuzzy diagnosis (FD).

Some taxonomic keys were designed in the system, in which each item including three components, namely id1 (serial number of the retrieval item), diagnostic characteristic and id 2 (serial number of the retrieval item related to id1) or result. When diagnosing the pests, the items will be provided to the user for selection and then be located to the next item according to the user's selection until the result is given (Fig. 2A).

When fuzzy diagnosis style is used by the user, a characteristic table should be submitted on the Internet Explorer to make the algorithm on the application layer partly or completely. The structure of the tables was designed by the experts with considerations of some diagnostic characteristics that are crucial to the pest diagnosis. The weight coefficient of each characteristic would be evaluated along to their importance. And then a specific table will be produced for a crop or a type of pest for 
diagnosis. The characteristic values of each kind of pest should be added to the database as many as possible by the experts before diagnosing. When diagnosing, the users select one crop or one type of pests, and then fill a table partly or completely, the result or the result list will be given with accurate probability (Fig. 2B).

\section{The Construction of the Information Service Platform}

\subsection{The Modules of the Web-Based ISP}

The web-based ISP is composed of six modules as shown in Fig. 3: information of the pests (pest name, symptoms, incidence, control method, and so on, were included in this module), search and diagnosis (the main module of the system, by which the users can search a pest or make diagnosis of an unknown pest), instruction for pest control (some control methods or some management advice for pests was given in this module), technology BBS (this module provides a open platform for the users and the experts to exchange their ideas or ask for help), system management (a module specific to the web manager), and relative references (some research references about the protected crop pests were collected in this module).

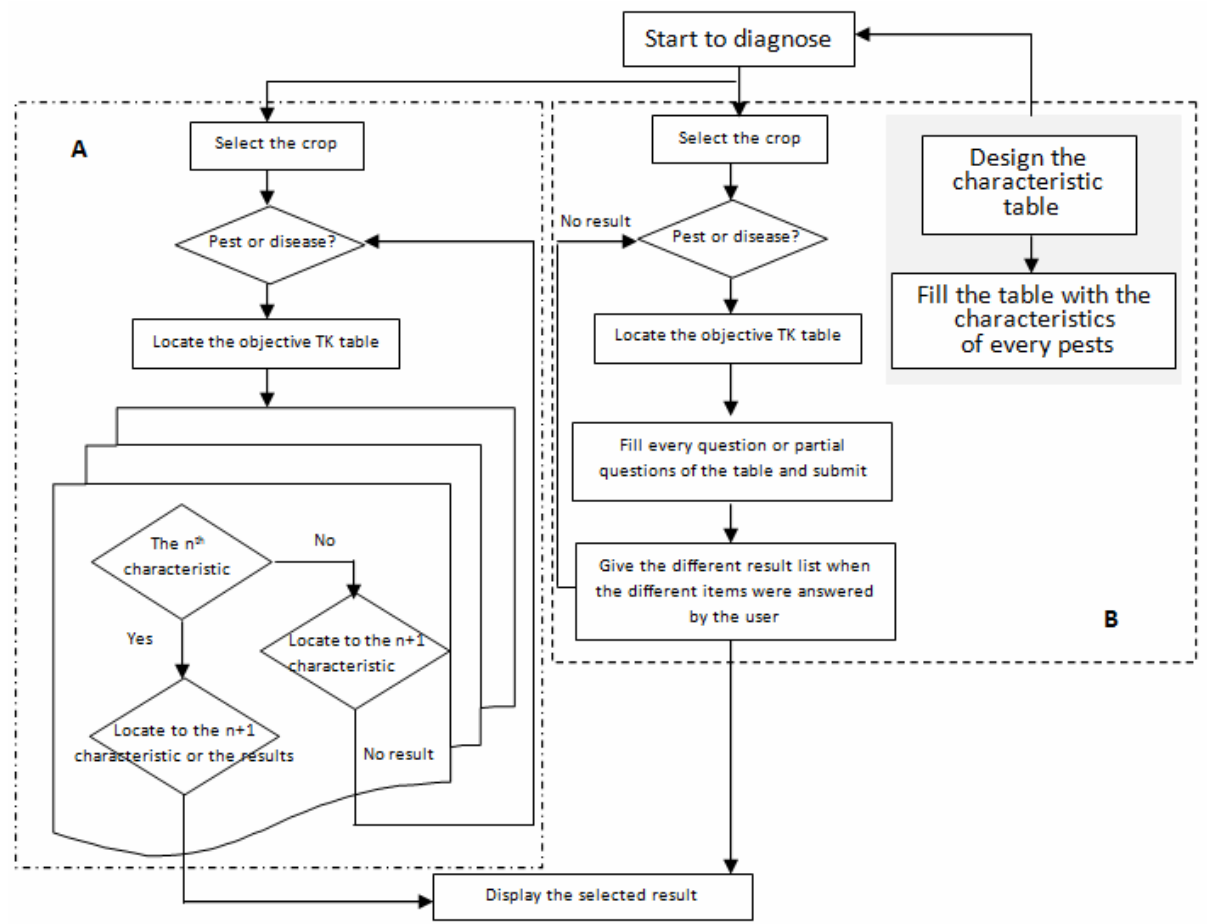

Fig. 2. Logical algorithms of binary tree structural taxonomic key (A) and fuzzy diagnosis (B) for the aided diagnosis 


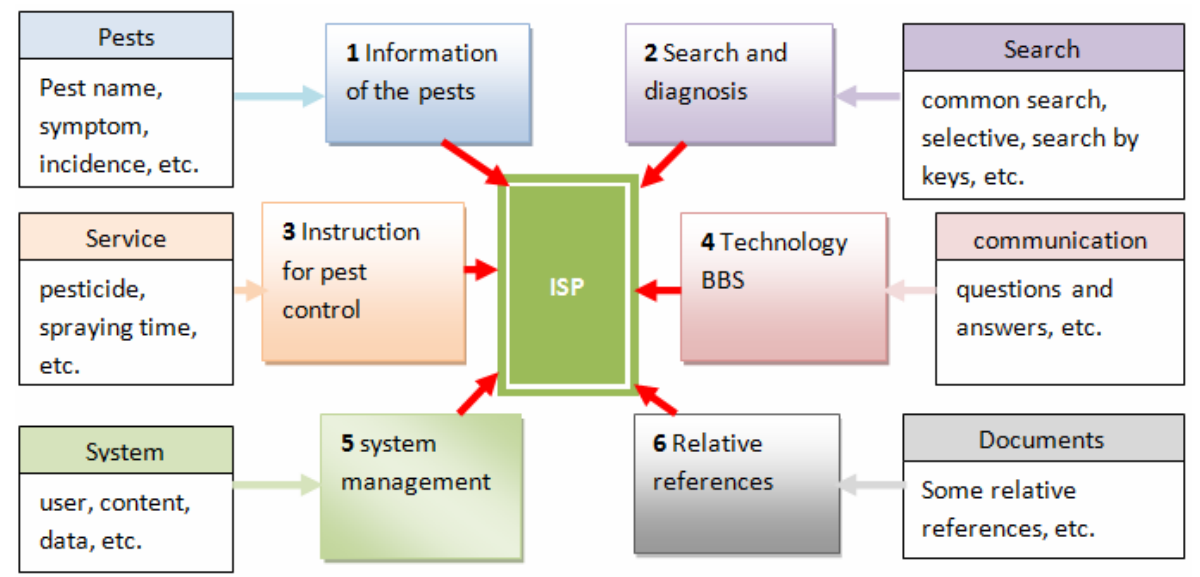

Fig. 3. The structure of the web-based information service platform

\subsection{The Functions of the Web-Based ISP}

Information service. In the web-based ISP, it is easy for the users to search some useful information such as pest information, pest control advice, and relative research papers through our own search engine or by the Google engine. When searching the information of a specific pest, the pest name is needed. The users can also search the information of a specific pest by inputting some information such as infested host, symptom, infesting period, and so on (Fig. 4A), a pest list satisfying the search conditions will be provided to the users by the platform, and then the users can choose what they need from the list. Pest control methods and lots of research advances are also available in the web-based ISP.

Pest diagnosis. Pest diagnosis is the key function of the web-based ISP. It can not only help the users to determine what the pest is, but provide some advices for them. When running the algorithms of taxonomic key (Fig. 4B), some pests are given and some pests are excluded when the diagnosis going on. When some selections and decisions have been done by the users on the Internet Explorer according to the items or the figures to run the logical algorithms of diagnosis in the internet information services, the result will appear on the computer screen (Fig. 4D).

Technology communication. BBS was designed in the web-based ISP enabling the experts and the users to exchange their ideas about protected crop pests. In the BBS, the users can ask questions, and the experts can answer the users' questions.

System and database management. System management module was designed for the web administrator. In the registration interface, the administrator inputs the user name and the corresponding password, and then log in the system management interface. The administrator can manage the columns of the system and conduct the data maintenance including adding data, modifying data, deleting data and so on. 

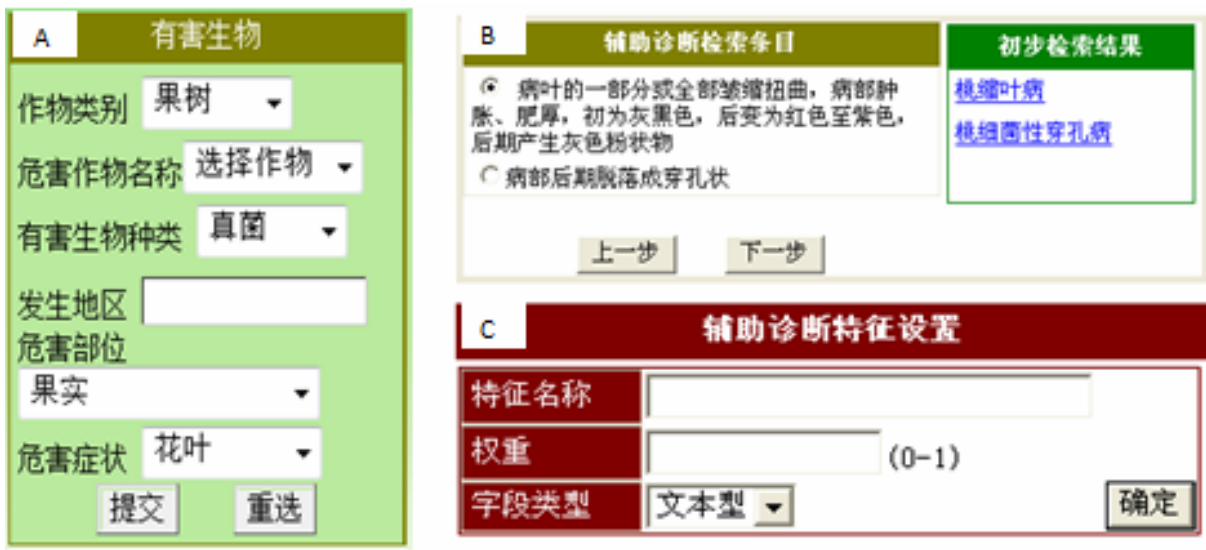

\begin{tabular}{|c|c|}
\hline D & 论断特征表 \\
\hline 特征 & 取值 \\
\hline 危雪时期 & 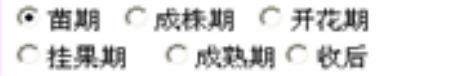 \\
\hline 危嘼部位 & 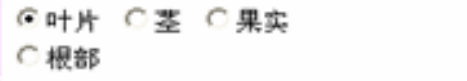 \\
\hline 病部特征 & 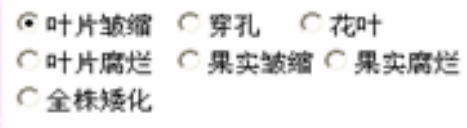 \\
\hline \multirow[t]{2}{*}{ 病应 } & 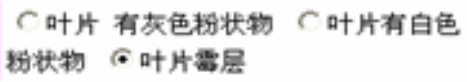 \\
\hline & 提交开始垥断 \\
\hline
\end{tabular}

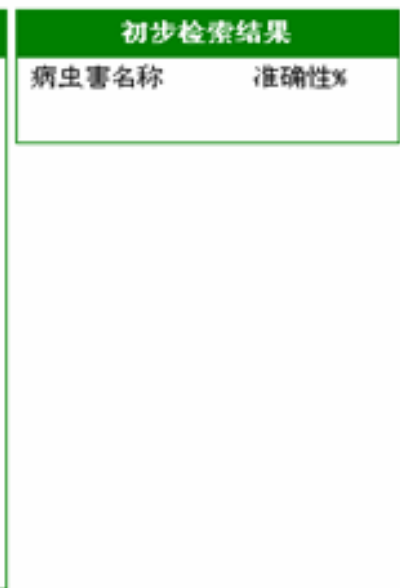

Fig. 4. The diagnostic functions of the web-based ISP

\section{Conclusion and Discussion}

A web-based information service system has been developed for protected crop pests to provide information service and aided diagnosis for the users including decision makers, agricultural technique extension workers and farmers. Through this system, the users can get pests' information and control methods. When an unknown pest occurring, the users can also use the function of aided diagnosis to determine what it is and how to control it. In the web-based ISP, two logical algorithms were designed for pest diagnosis. One was based on the identification key that was widely used in the taxonomic. The accuracy of the method mostly depends on the identification key. And another was a probabilistic diagnosis.

With the development of information technology and the improvement of living standard, more and more Chinese farmers who are eager to obtain the technology to instruct their production, can get access to the internet and obtain the agricultural 
knowledge and the technology guidance from web-based information service platform. The platform we developed could promote the spread and the popularization of the knowledge about protected crop pest and could efficiently relieve the shortage of agricultural experts and agricultural technique extension workers.

In further studies, more pest information would be added into the platform. And the platform could provide video information in addition to the texts and the images. The function of image assistant diagnosis could also be added into the platform so that the users could get diagnosis result when they upload one image of an unknown pest. The platform could combine with Geographic Information System (GIS) to provide pest information in certain area [11, 12, 13, 14, 15]. With more understanding of protected crop pests, the function of pest forecast may be added to the platform. Using pest forecast, occurrence information of protected crop pests could be provided to the farmers earlier, so they could make enough preparation as early as possible.

Pest management is a part of protected crop production management. Some crop production management systems have been developed [16, 17]. Most of them contain the pest management module or subsystem. On the whole, the crop production management systems make important contribution to crop production management and improve the level of agricultural production management. In order to drive the development of protected crop industry, it is necessary to develop the production management system for protected crops on the base of this platform in further researches.

Acknowledgements. This research was supported by Project in the National Science \& Technology Pillar Program during the Eleventh Five-year Plan Period of China (Grant No: 2007BAD57B02).

\section{References}

1. Wang, H.G., Ma, Z.H., Zhang, M.R., Shi, S.D.: Application of Computer Technology in Plant Pathology. Agriculture Network Information 10, 31-34 (2004) (in Chinese)

2. Ren, H.X., Gao, L.W.: Research Progress on Expert System Technology and its Application in Plant Protection. China Plant Protection 11, 11-14 (2007) (in Chinese)

3. Liu, Q.H., Xiao, M., Li, K.L.: The Wheat Diseases Expert System Based on the Web and the Implementation Using the Java Technology. Computer Engineering and Applications 34, 210-212, 225 (2003) (in Chinese)

4. Wu, B.G., Wen, L.B.: Expert Consulting System for the Diagnosis, Prevention and Control of Important Forest Diseases and Insect Pests. Journal of Beijing Forestry University 28, 113-118 (2006) (in Chinese)

5. Shao, G., Li, Z.H., Wang, W.R., Zhou, Q.F., Yan, X.J., Zheng, J.Q., Shi, Y.C.: Study on Vegetable Pests Remote Diagnosis Expert System (VPRDES). Plant Protection 32, 51-54 (2006) (in Chinese)

6. Ying, M., Li, S.Q.: Analysis and Research on Web-based Grape Diseases Intelligent Decision Support System. Journal of Agricultural Mechanization Research 30, 35-38 (2008) (in Chinese)

7. Jin, Y., Shi, X.H., Xiong, X.Y., Cao, X.J., Wei, Y.: Grape Diseases Diagnose Expert System Based on Artificial Neural Network. Computer Engineering and Applications 45, 215 217 (2009) (in Chinese) 
8. Tan, S.Q., Yin, F.Z., Zhang, G., Cao, Y.M.: Realization of Long-distance Diagnosis of Forest Disease and Pest. Journal of Central South University of Forestry \& Technology 29, 189-192 (2009) (in Chinese)

9. Li, Y.S., Su, F., Hong, L.F., Fu, L.B., Chen, H.: Study and Development on the Information Query System of Tobacco Pests \& Diseases. Southwest China Journal of Agricultural Sciences 22, 324-328 (2009) (in Chinese)

10. Huang, C., Wang, H.G., Zhang, Y.: Development of Information Retrieval and Aided Diagnosis System for Protected Crop Pests. Journal of Agricultural Mechanization Research 32, 139-142 (2010) (in Chinese)

11. Yang, Z.F., Liu, G., Ma, Y.X., Liu, W.: Research on Fruit Tree Plant Diseases and Insect Pests Publication System Based on WebGIS. Journal of Agricultural University of Hebei 28, 88-91, 96 (2005) (in Chinese)

12. Wang, A.C., Miao, T.Y., Cao, J.: Study of Web-based Expert System for Control Diseases and Insects in Forest. Computer Technology and Development 18, 228-231, 235 (2008) (in Chinese)

13. Gong, Y.P., Huang, W.J., Pan, Y.C., Xu, X.G., Liu, L.Y., Wang, J.H., Yan, G.J.: Construction of a WebGIS-based Forecast System of Crop Diseases and Pests. Journal of Natural Disasters 17, 36-41 (2008) (in Chinese)

14. Li, F.J., Liu, X.J., Jing, H.Y., Cao, W.X., Zhu, Y.: Study on WebGIS and Knowledge Model Based Decision Support System for Disease-pest-weed Management in Wheat. Journal of Triticeae Crops 29, 934-940 (2009) (in Chinese)

15. Liu, T.H., Gao, M.X., Wang, L., Li, X.: The Study and Construction of Winter-Jujube Pest and Disease Information Forum Based on WebGIS. Northern Horticulture 2, 232-234 (2010) (in Chinese)

16. Qiu, J.J., Xiao, Y.N., Dai, Y.M., Hu, X.N., Wang, R., Lin, H.: Cotton Production Management System Based on the Cotton Plus Model for Xinjiang and Huang-Huai-Hai Region in China. Transactions of CSAE 18, 161-164 (2002) (in Chinese)

17. Li, J.Y., Suo, X.S., Zhang, Z.P., Zhang, S.G.: Expert System of Wheat and Corn Production Management Based on WEB. Journal of Agricultural Mechanization Research 27, 128-131 (2005) (in Chinese) 